\title{
Identification of major milk fat globule membrane proteins from pony mare milk highlights the molecular diversity of lactadherin across species
}

\author{
C. Cebo, ${ }^{\star 1}$ E. Rebours, ${ }^{\star}$ C. Henry, $†$ S. Makhzami, ${ }^{\star} †$ P. Cosette, $\neq$ and P. Martin ${ }^{\star}$ \\ *INRA, UMR1313 Unité Génétique Animale et Biologie Intégrative, F-78350 Jouy-en-Josas, France \\ †INRA, Plateforme PAPSSO (Plateforme d'Analyse Protéomique Paris Sud Ouest), F-78350 Jouy-en-Josas, France \\ łUMR6270 CNRS, Université de Rouen, Plateforme Protéomique de l'IFRMP23, F-76821 Mont-Saint-Aignan Cedex, France
}

\section{ABSTRACT}

Although several studies have been devoted to the colloidal and soluble protein fractions of mare milk (caseins and whey proteins), to date little is known about the milk fat globule membrane (MFGM) protein fraction from mare milk. The objective of this study was thus to describe MFGM proteins from Equidae milk and to compare those proteins to already described MFGM proteins from cow and goat milk. Major MFGM proteins (namely, xanthine oxidase, butyrophilin, lactadherin, and adipophilin) already described in cow or goat milk were identified in mare milk using mass spectrometry. However, species-specific peculiarities were observed for 2 MFGM proteins: butyrophilin and lactadherin. A highly glycosylated $70-\mathrm{kDa}$ protein was characterized for equine butyrophilin, whereas proteins of 64 and $67 \mathrm{kDa}$ were characterized for cow and goat butyrophilin, respectively. Prominent differences across species were highlighted for lactadherin. Indeed, whereas 1 or 2 polypeptide chains were identified, respectively, by peptide mass fingerprinting matrix-assisted laser desorption/ionization-time of flight analysis for caprine and bovine lactadherin, 4 isoforms $(60,57,48$, and $45 \mathrm{kDa})$ for lactadherin from mare milk were identified by $10 \%$ sodium dodecyl sulfate-PAGE. Polymerase chain reaction experiments on lactadherin transcripts isolated from milk fat globules revealed the existence of 2 distinct lactadherin transcripts in the horse mammary gland. Cloning and sequencing of both transcripts encoding lactadherin showed an alternative use of a cryptic splice site located at the end of intron 5 of the equine lactadherin-encoding gene. This event results in the occurrence of an additional alanine (A) residue in the protein that disrupts a putative atypical $\mathrm{N}$-glycosylation site (VNGC/VNAGC) described in human lactadherin. Liquid chromatography coupled with tandem mass spectrometry analyses confirmed the exis-

Received April 15, 2011.

Accepted November 13, 2011.

${ }^{1}$ Corresponding author: christelle.cebo@jouy.inra.fr tence of both lactadherin variants in mare MFGM. We show here that lactadherin from Equidae milk is much more complex than that from Bovidae milk (i.e., cow and goat milk), therefore raising questions regarding the precise function of these different isoforms, if any, in the equine mammary gland.

Key words: milk fat globule membrane, Equidae, lactadherin, alternative splicing

\section{INTRODUCTION}

Mare milk is widely consumed throughout Eastern Europe and Asia as kumis (or koumiss), a mildly alcoholic beverage produced by fermentation of milk. In Western Europe, interest in mare milk is growing. It has been suggested that mare milk could be a good substitute for cow milk in children with severe IgEmediated cow milk allergy (Businco et al., 2000). Mare milk shows some differences compared with cow and human milk. The protein content in mare milk is between that of human and bovine milk. The fat content is lower in mare milk compared with that in human and cow milk, but the percentage of unsaturated fatty acids in mare and human milk is similar and higher than in cow milk (Malacarne et al., 2002). Mare milk has been extensively characterized with regard to the casein and whey protein fractions. Most of the milk proteins, $\kappa-$, $\alpha_{\mathrm{S1}^{-}}, \alpha_{\mathrm{S} 2^{-}}$, and $\beta-\mathrm{CN}$, lysozyme $\mathrm{C}, \alpha-\mathrm{LA}$, and $\beta-\mathrm{LG}$, were identified in Equidae milk using proteomic tools (Miranda et al., 2004). Recent studies on mare milk have focused on the characterization of $\alpha_{\mathrm{S}^{-}}$and $\beta-\mathrm{CN}$, which are highly polymorphic in the horse species. Results revealed the existence of a full-length $\alpha_{\mathrm{S}_{1}} \mathrm{CN}$ and 7 variants resulting from exon-skipping events involving exon 7, exon 14, or both, and use of a cryptic splice site encoding a glutamine residue at the beginning of exon 11 of the equine $\alpha_{\mathrm{S}^{-}} \mathrm{CN}$ gene. Consequently, 36 variants of equine $\alpha_{\mathrm{S}^{-}} \mathrm{CN}$ were identified, with several phosphate groups ranging from 2 to 8 depending on whether exon 7 was skipped (Matéos et al., 2009, 2010). Alternative splicing has also been reported for equine $\beta$-CN. An internally truncated form of the full-length 
equine $\beta-\mathrm{CN}$ has recently been shown (Miclo et al., 2007). This low molecular weight variant displays a large deletion (residues 50-181 of the full-length $\beta-\mathrm{CN}$ ) due to a cryptic splice site occurring within exon 7 of $\beta$-CN primary transcript. Interestingly, the occurrence of the low molecular weight $\beta$-CN variant was reported in several horse breeds, but this variant is apparently absent from the milk of other mammalian species studied to date (Miclo et al., 2007). Thus, some alternative splicing events seem to be specific to the Equidae.

In the Equidae, studies about the milk fat globule membrane (MFGM), the membrane deriving from the apical plasma membrane of the mammary epithelial cell and surrounding the triglyceride core in milk (Mather and Keenan, 1998), are scarce and are essentially devoted to the analysis of fat fractions (Barello et al., 2008). On the other hand, in-depth proteomic studies have been published for human (Quaranta et al., 2001), bovine (Reinhardt and Lippolis, 2006), water buffalo (D'Ambrosio et al., 2008), and more recently, ovine (Pisanu et al., 2011) MFGM proteins. These large-scale studies, undoubtedly useful with regard to the identification of the whole MFGM protein compartment, do not reflect the molecular diversity of MFGM proteins across species. An inter-species comparison of milk proteins may help to understand the structure-function relationship hypothesized for some MFGM proteins. Consequently, we focused our attention on the identification of the major MFGM proteins from mare milk. In addition, based on our previous report on MFGM proteins from goat milk (Cebo et al., 2010), we provide an interspecies comparison of major MFGM proteins from cow, goat, and mare milk. Results show high speciesto-species variation especially regarding lactadherin, a major protein of the MFGM. Both posttranscriptional (splicing variants) and posttranslational (glycosylation variants) isoforms were identified for equine lactadherin. Finally, our findings are discussed with regard to literature data about lactadherin across species.

\section{MATERIALS AND METHODS}

\section{Animals and Milk Samples}

Individual milk samples were collected at $133 \pm 11$ d postpartum from 5 primiparous and 1 multiparous Welsh mares aged 3 to $11 \mathrm{yr}$, with an average BW after foaling of $348.7 \pm 49.6 \mathrm{~kg}$ from an INRA experimental farm (Unité Expérimentale de Physiologie animale de l'Orfrasière, Nouzilly, France). The mare and foal were separated for $1 \mathrm{~h}$ before milking to increase milk yield. Then, the foal was brought back to the mare but was not allowed to suckle. Five hundred microliters of an oxytocin solution (Ocytovem, $10 \mathrm{UI} / \mathrm{mL}$, Virbac, Car- ros, France) was administered to the mare followed by hand-milking in the presence of the foal. Milk samples were then centrifuged at $1,000 \times g$ for $10 \mathrm{~min}$ at $10^{\circ} \mathrm{C}$. Fat globules were recovered in the supernatant layer and stored at $-80^{\circ} \mathrm{C}$ for subsequent analysis. For protein extraction, fat globules were washed twice with 10 $\mathrm{mL}$ of $0.9 \%$ (wt/vol) $\mathrm{NaCl}$ to remove residual caseins and whey proteins eventually adsorbed to fat globules.

\section{Extraction and Analysis of MFGM Proteins}

The MFGM proteins were extracted from milk fat with an SDS-containing solution as described previously (Fortunato et al., 2003) with some modifications. Briefly, lysis buffer (63 mM Tris-HCl, pH 9, 2\% SDS supplemented with a protease inhibitor cocktail; Complete Mini, EDTA-free, Roche Diagnostics, Meylan, France) was added to washed fat globules, incubated for $1 \mathrm{~h}$ at $20^{\circ} \mathrm{C}$ with periodic vortexing, and centrifuged at $10,000 \times g$ for $10 \mathrm{~min}$. The floating cream layer was removed and lysates were centrifuged again and then stored at $-80^{\circ} \mathrm{C}$ for further analysis. Protein concentration (Lowry's method) was assessed with the Bio-Rad RC-DC Protein Assay according to the instructions of the manufacturer (Bio-Rad, Marnes-la-Coquette, France). Proteins were resolved by SDS-PAGE, stained with Bio-Safe Coomassie (Bio-Rad Laboratories) or electrotransferred onto nitrocellulose for immunoblotting with antibodies or lectins.

\section{Periodic Acid-Schiff Staining}

For total glycoprotein analysis, $100 \mu \mathrm{g}$ of protein was separated on $6 \%$ acrylamide gels $(4.5 \%$ acrylamide for the stacking gel) and revealed with the Schiff reagent (Sigma-Aldrich, Bio-Rad) in accordance with the protocol of the manufacturer. Briefly, gels were fixed overnight in $40 \%$ ethanol $/ 7 \%$ acetic acid and washed 2 times (30 $\mathrm{min}$ each) with fresh fixative solution. Carbohydrates were oxidized for $1 \mathrm{~h}$ by immersing gels in a solution of $1 \%$ periodic acid $/ 3 \%$ acetic acid, and were then washed 10 times (10 min each) with water to remove traces of periodic acid. Gels were immersed for $1 \mathrm{~h}$ in the Schiff reagent in the dark to reveal the glycoprotein bands, and were then washed for $15 \mathrm{~min}$ with water. Images were immediately acquired after washing.

\section{Analysis and Identification of Proteins}

Proteins were excised from the one-dimensional gel and gel pieces were washed twice in ultrapure water followed by 2 washes in $50 \%$ acetonitrile $(\mathbf{A C N})$ and $50 \mathrm{~m} M$ ammonium bicarbonate $\left(\mathrm{NH}_{4} \mathrm{HCO}_{3} ; \mathrm{vol} / \mathrm{vol}\right)$. 
After gel-drying for $10 \mathrm{~min}$, the digestion was per-

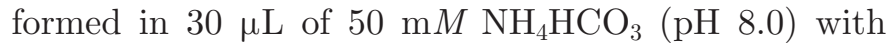
$0.2 \mu \mathrm{g}$ of modified trypsin (sequencing grade, Promega, Charbonnières, France) for $16 \mathrm{~h}$ at $37^{\circ} \mathrm{C}$. The identity of peptides was obtained using a Voyager DE super STR matrix-assisted laser desorption/ionization-time of flight (MALDI-TOF) mass spectrometer (Applied Biosystems, Foster City, CA) equipped with a nitrogen laser emitting at $337 \mathrm{~nm}$. One microliter of tryptic digest was mixed on the stainless steel MALDI plate with $1 \mu \mathrm{L}$ of $\alpha$-cyano-4-hydroxycinnamic acid (SigmaAldrich, Saint Quentin Fallavier, France) at $5 \mathrm{mg} / \mathrm{mL}$ in $\mathrm{ACN} / 0.3 \%$ trifluoroacetic acid (TFA; vol $/ \mathrm{vol}$ ) and dried at room temperature. Spectra were recorded in positive reflector mode with $20 \mathrm{kV}$ as accelerating voltage, a delayed extraction time of $120 \mathrm{~ns}$, and a $63 \%$ grid voltage. Internal mass calibration was performed using tryptic autolysis peptides $[\mathrm{M}+\mathrm{H}]^{+}=842.51$ and $[\mathrm{M}+\mathrm{H}]^{+}=2211.11$. Mass spectra were treated by Data Explorer 4.2 (Applied Biosystems) with the following parameters: baseline correction, noise removal of 2 , and peak resolution of 10,000. Spectral profiles were collected in the mass:charge ratio $=800$ to 3,000 Da. All peptide masses were assumed to be monoisotopic and protonated molecular ions $[\mathrm{M}+\mathrm{H}]^{+}$. Proteins were identified among Swiss-Prot and TrEMBL databases using the Aldente Peptide Mass Fingerprinting tool from Expasy website (http://www.expasy.org/tools/aldente/) with the following parameters: trypsin specificity, one missed cleavage, 30 ppm mass accuracy, carbamidomethylation and methionine oxidation as fixed and variable modifications, respectively.

\section{In-Gel Digestion and Liquid Chromatography-Tandem MS Analysis}

Bands from SDS-PAGE gels were cut and in-gel digestion was performed with the Progest system (Digilab, Holliston, MA) according to a standard trypsin protocol. Gel pieces were washed twice with successive separate baths of $10 \%$ acetic acid, $40 \%$ ethanol, and acetonitrile, and then washed twice with successive baths of $25 \mathrm{mM} \mathrm{NH}_{4} \mathrm{CO}_{3}$ and ACN. After gel drying, reduction with $10 \mathrm{~m} M$ dithiothreitol in $25 \mathrm{mM} \mathrm{NH}_{4} \mathrm{HCO}_{3}$ and alkylation with $55 \mathrm{mM}$ iodoacetamide in $25 \mathrm{mM}$ $\mathrm{NH}_{4} \mathrm{HCO}_{3}$ were performed. Digestion was subsequently achieved for $6 \mathrm{~h}$ at $37^{\circ} \mathrm{C}$ with $125 \mathrm{ng}$ of modified trypsin (Promega) dissolved in 20\% methanol and $20 \mathrm{mM}$ $\mathrm{NH}_{4} \mathrm{CO}_{3}$. Peptides were extracted successively with $2 \%$ TFA and 50\% ACN and then with ACN. Peptide extracts were dried in a vacuum centrifuge and suspended in $20 \mu \mathrm{L}$ of $0.08 \% \mathrm{TFA}$ and $2 \% \mathrm{ACN}$. The HPLC was performed on an Ultimate 3000 liquid chromatography (LC) system (Dionex, Voisins Le Bretonneux, France).
A $4-\mu \mathrm{L}$ sample was loaded at $20 \mu \mathrm{L} / \mathrm{min}$ on a $\mathrm{C} 18$ PepMap 100 precolumn cartridge ( $5 \mu \mathrm{m}$, column: 300 $\mu \mathrm{m}$ i.d., $5 \mathrm{~mm}$ long; Dionex) and desalted with $0.08 \%$ TFA and $2 \% \mathrm{ACN}$. After $4 \mathrm{~min}$, the precolumn cartridge was connected to the separating C18 PepMap C18 100 column $(3 \mu \mathrm{m}$, column: $75 \mu \mathrm{m}$ i.d., $150 \mathrm{~mm}$ long; Dionex). Buffers were $0.1 \% \mathrm{HCOOH}-2 \% \mathrm{ACN}$ (A) and $0.1 \% \mathrm{HCOOH}-80 \% \mathrm{ACN}(\mathrm{B})$. The peptide separation was achieved with a linear gradient from 0 to $36 \% \mathrm{~B}$ for $18 \mathrm{~min}$, at $300 \mathrm{~nL} / \mathrm{min}$. Including the regeneration step at $100 \% \mathrm{~B}$ and the equilibration step at $100 \%$ A, 1 run took 50 min. Eluted peptides were analyzed on-line with a LTQ-Orbitrap mass spectrometer (Thermo Electron, Courtaboeuf, France) using a nanoelectrospray interface. Ionization $(1.3 \mathrm{kV}$ ionization potential) was performed with liquid junction and a capillary probe $(10 \mu \mathrm{m}$ i.d.; New Objective, Woburn, MA). Peptide ions were analyzed using Xcalibur 2.07 with the following data-dependent acquisition steps: (1) full scan positive mode spectra were measured between $m / z 300$ and 1,600 , and (2) tandem MS (MS/MS) in linear trap ( $\mathrm{qz}=0.25$, activation time $=30 \mathrm{~ms}$, and collision energy $=45 \%$; centroid mode). Step 2 was repeated for the 4 most abundant ions detected in step 1. Dynamic exclusion time was set to $90 \mathrm{~s}$.

A database search was performed with XTandem 2008.02.01 (http://www.thegpm.org/TANDEM/). Enzymatic cleavage was declared as a trypsin digestion with one possible miscleavage. Cysteine carboxyamidomethylation and methionine oxidation were set to static and possible modifications, respectively. Precursor mass and fragment mass tolerance were $10 \mathrm{ppm}$ and $0.5 \mathrm{Da}$, respectively. A refinement search was added with similar parameters except that semi-tryptic peptide and possible $\mathrm{N}$-terminal protein acetylation were searched. Databases used were the Equus caballus database from NCBI (http://www.ncbi.nlm.nih.gov/Taxonomy/Browser/wwwtax.cgi?id=9796; 21,325 entries), the Equus caballus Ensembl database (http://www. ensembl.org/info/data/ftp/index.html; 22,641 entries), and a contaminant database (porcine trypsin, human keratins). Only peptides with an $\mathrm{E}$ value $<0.1$ were reported. Identified proteins were filtered according to: (1) a minimum of 2 distinct peptides was required with an $\mathrm{E}$ value $<0.05,(2)$ a protein $\mathrm{E}$ value $<10^{-4}$. In the case of identification with only 2 or $3 \mathrm{MS} / \mathrm{MS}$ spectra, similarity between the experimental and the theoretical MS/MS spectra was visually checked.

\section{N-Terminal Sequencing}

For $N$-terminal sequencing, $100 \mu \mathrm{g}$ of MFGM proteins was precipitated using the methanol-chloroform method (Wessel and Flügge, 1984) and then proteins 
were resolubilized in Laemmli buffer. The MFGM proteins were resolved on 6\% SDS-PAGE and electrotransferred onto methanol prewetted polyvinylidene fluoride (PVDF) membranes. Proteins were stained with a $40 \%$ (vol/vol) ethanol-1\% (vol/vol) acetic acid solution containing $0.1 \%$ (wt/vol) Coomassie Brilliant Blue R-250, and then proteins were destained in a $50 \%$ (vol/vol) ethanol solution. The bands corresponding to the horse lactadherin isoforms were carefully excised and subjected to cycles of Edman degradation using an automatic protein sequencer (Procise P494, Applied Biosystems).

\section{Western Blotting Experiments}

Twenty micrograms of MFGM proteins was resolved by $6 \%$ SDS-PAGE and electrotransferred onto nitrocellulose for immunoblotting. To avoid nonspecific binding, blots were immersed for $1 \mathrm{~h}$ at $20^{\circ} \mathrm{C}$ in Trisbuffered saline (TBS) solution containing 1\% (wt/vol) NDM and 1\% (wt/vol) polyvinylpyrrolidone (Sigma). Blots were briefly rinsed in TBS and probed $2 \mathrm{~h}$ at room temperature in TBS 0.1\% Tween-20 (Sigma) with antibodies against bovine lactadherin $(1 / 10,000$, kindly provided by J. T. Rasmussen, Department of Molecular Biology, Aarhus University, Denmark). Blots were then washed extensively in TBS $0.1 \%$ Tween-20 and incubated with goat anti-rabbit secondary antibodies coupled to horseradish peroxidase $(1 / 5,000$, Interchim, Montluçon, France). Immunocomplexes were revealed by the enhanced chemiluminescence system (Dutscher, Brumath, France). Quantification of lanes was performed using ImageJ software (http://rsb.info.nih.gov/ $\mathrm{ij} /)$.

\section{Treatment of MFGM Proteins with Peptide $\mathrm{N}$-glycosidase from Flavobacterium meningosepticum}

The MFGM protein samples $(100 \mu \mathrm{g})$ were digested with $10 \mathrm{U}$ of peptide $\mathrm{N}$-glycosidase (PNGase F, EC 3.5.1.52) from Flavobacterium meningosepticum (Sigma) in $250 \mathrm{mM}$ phosphate buffer, $\mathrm{pH} 7$, containing $0.1 \%$ SDS (wt $/ \mathrm{vol}$ ) and $5 \%$ (vol/vol) 2-mercaptoethanol. Denaturation of proteins was performed by heating samples at $95^{\circ} \mathrm{C}$ for $5 \mathrm{~min}$. Samples were cooled and then Triton X-100 was added at the final concentration of $0.5 \%$ ( $\mathrm{vol} / \mathrm{vol})$. Two microliters $(10 \mathrm{U})$ of the PNGase $\mathrm{F}$ solution was added to protein mixtures. Samples were then incubated for $3 \mathrm{~h}$ at $37^{\circ} \mathrm{C}$. Control samples (without enzyme) were similarly handled. After the incubation step, MFGM proteins were precipitated using the methanol-chloroform method (Wessel and Flügge, 1984) and proteins were solubilized in the
Laemmli buffer. Cleavage of $N$-linked oligosaccharides on MFGM proteins was monitored by SDS-PAGE. Identity of MFGM proteins after PNGase F treatment was confirmed by peptide mass fingerprinting (PMF) MALDI-TOF analysis. Efficiency of $\mathrm{N}$-glycosidase digestion was evaluated using Ribonuclease B from bovine pancreas (Sigma Laboratories) as a substrate. Ribonuclease B molecular weights were 17 and $14 \mathrm{kDa}$ for the $N$-glycosylated and the full- $N$-deglycosylated protein, respectively. Efficiency of $N$-deglycosylation in these conditions was assumed to be almost complete $(>95 \%)$.

\section{RNA Isolation and Analysis of Equine Lactadherin Transcripts}

Milk samples were centrifuged at 1,000 $\times g$ for $10 \mathrm{~min}$ at $10^{\circ} \mathrm{C}$. Total RNA from 2 individuals was extracted from milk fat globule material as described previously (Maningat et al., 2009). The concentration of RNA was determined using Nanodrop 1000 spectrophotometer reading of absorbance at $260 \mathrm{~nm}$ (Thermo Fisher Scientific, Rockford, IL), and RNA quality was assessed with Agilent RNA 6000 LabChips (Agilent Technologies, Massy, France). The RNA integrity numbers of all samples were at least 8; RNA (500 ng) was reverse transcribed by using the Superscript III reverse transcriptase and a mix of oligo-dT and random primers (3:1 molar ratio; Life Technologies, Villebon-sur-Yvette, France). Prior to PCR amplification, cDNA templates were denatured at $95^{\circ} \mathrm{C}$ for $2 \mathrm{~min}$. Each PCR reaction was carried out with 40 cycles at $95^{\circ} \mathrm{C}$ for $1 \mathrm{~min}$ (denaturation), $58^{\circ} \mathrm{C}$ for $1 \mathrm{~min}$ (annealing), and $72^{\circ} \mathrm{C}$ for $3 \mathrm{~min}$ (extension). A final extension step was added $\left(72^{\circ} \mathrm{C}\right.$ for $\left.5 \mathrm{~min}\right)$. The PCR products were analyzed by $1 \%$ agarose gel electrophoresis. The primers used were (from $5^{\prime}$ end to $3^{\prime}$ end): TTC TGT GAC TCC AGC CAG TG (P1; forward), GTG AAC CTC ATG CGG AAG AT (P4; forward), GTC CCT CTG GAG GTG CAG TA (P5, forward), GTT GAA CTT GCC CTG CTT GT (P6, reverse), AGG AAG GGC GTC TCA AAC AT (P8; reverse) and GTC ACA CAT GCC CTA CTT CG (R, reverse). The primer pair P1/P8 specifically amplifies horse lactadherin transcripts from exon 1 to exon 8 (PCR product size: 1,139 bp), whereas the $\mathrm{P} 4 / \mathrm{P} 8, \mathrm{P} 5 / \mathrm{P} 6$, and $\mathrm{P} 1 / \mathrm{R}$ primer pairs produce 704-, 237-, and 1,434-bp PCR fragments, respectively. The PCR products were sequenced by Eurofins MWG GmbH (Ebersberg, Germany) and translated in silico using the "Translate" tool at the Swiss Institute of Bioinformatics (http://www.expasy.org/tools/dna. html). $N$-Glycosylation sites were predicted using the NetNGlyc 1.0 Server (http://www.cbs.dtu.dk/services/ NetNGlyc/). 
Sizing of amplified DNA fragments was performed either in 4\% (wt/vol) agarose gels followed by staining with ethidium bromide or using the Agilent 2100 Bioanalyzer with the DNA 7500 kit (Agilent Technologies). Before electrophoresis on microfluidic chips, PCR products were diluted 1:10 with sterile water. According to the manufacturer's instructions, sizing resolution was $\pm 5 \%$ in the 100 to 1,000 bp range and $\pm 15 \%$ in the 1,000 to $7,500 \mathrm{bp}$ range.

For cloning experiments, PCR products were purified by ethanol precipitation. The washed pellet was air-dried and resuspended in $15 \mu \mathrm{L}$ of RNase-DNasefree water. The PCR products were integrated to the TOPOr vector according to the manufacturer's protocol (TOPO TA Cloning kit for sequencing, Invitrogen Life Technologies). Colonies were screened by using M13 primers (forward and reverse), and M13 PCR products (from 24 positive colonies) were purified by ethanol precipitation and sequenced in both directions.

\section{RESULTS}

\section{Main Features of MFGM Proteins from Mare Milk}

Figure 1 shows a representative 10\% SDS-PAGE pattern of MFGM samples extracted from mare (lanes 1-2), cow (lane 3), and goat (lane 4) milk. Major MFGM proteins from mare milk were identified by PMF MALDITOF MS analysis or LC-MS/MS (Figure 1 and Table 1). Although similarities across species can be shown for some MFGM proteins (most notably for xanthine oxidase), the protein profile of MFGM proteins from mare milk exhibited prominent differences from Bovidae milk, especially regarding the 2 major proteins: butyrophilin (band b, Figure 1), which migrated significantly more slowly, and lactadherin (bands c to f, Figure 1), which appeared much more complex, with several isoforms. In accordance with literature data (Aoki et al., 1994; Hvarregaard et al., 1996), bovine lactadherin (also known as PAS 6/7 glycoprotein) is detected as 2 glycoprotein bands, the lower band being mixed with adipophilin (Figure 1, lane 3). Lactadherin from goat milk (Figure 1, lane 4) appeared as a single band, as reported in our previous study (Cebo et al., 2010). On the other hand, $10 \%$ SDS-PAGE analysis of samples followed by MS/MS sequencing allowed identification of 4 bands corresponding to equine lactadherin within MFGM proteins from mare milk (Figure 1 (lanes 1-2, bands c-f) and Table 1). Apparent molecular weights for equine lactadherin isoforms (from top to bottom) were calculated as 60 (band c), 57 (band d), 48 (band e), and 45 (band f) kDa, respectively (Figure 1, lanes 1-2). Adipophilin (perilipin-2) was also identified in mare milk by LC-MS/MS analyses, being mostly mixed with the $48-\mathrm{kDa}$ isoform of

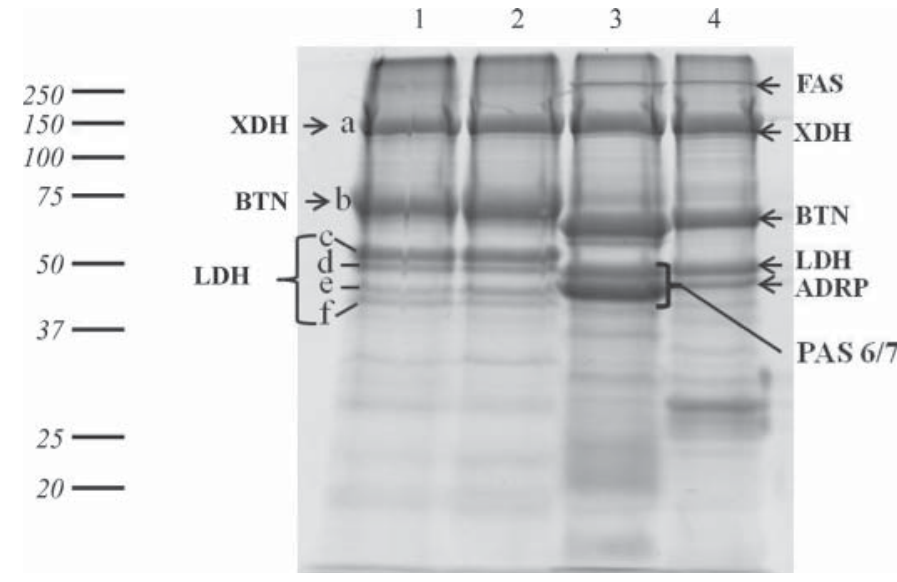

Figure 1. Representative pattern of mare milk fat globule membrane (MFGM) proteins in SDS-PAGE. The MFGM proteins from equine (lanes 1-2), bovine (lane 3), and caprine (lane 4) milk were separated on 10\% SDS-PAGE and stained with Biosafe (Bio-Rad, Marnes-la-Coquette, France). Proteins from the mare MFGM (bands a to $\mathrm{f}$ ) were identified using matrix-assisted laser desorption/ionization-time of flight (MALDI-TOF) or tandem mass spectrometry (MS/ MS) analysis (see Table 1). Positions of major proteins of the goat MFGM (Cebo et al., 2010) are indicated to the right of the gel. Bovine PAS 6/7 glycoproteins as described by Hvarregaard et al. (1996) are highlighted (lane 3). FAS = fatty acid synthase; $\mathrm{XDH}=$ xanthine oxidase; $\mathrm{BTN}=$ butyrophilin; $\mathrm{LDH}=$ lactadherin; $\mathrm{ADRP}=$ adipose differentiation-related protein, adipophilin. Positions of protein standards $(\mathrm{kDa})$ are indicated to the left.

lactadherin (Figure 1 and data not shown). Lactadherin from Equidae milk thus appeared much more complex than lactadherin from Bovidae milk.

\section{Equine Butyrophilin Is More Glycosylated than Its Ruminant Counterparts}

In contrast to equine lactadherin, which appears as several isoforms within MFGM proteins, equine butyrophilin can be identified by PMF MALDI TOF analyses as a single $70-\mathrm{kDa}$ protein, whereas proteins of 64 and $67 \mathrm{kDa}$ were characterized for cow and goat butyrophilin, respectively (Figure 1 and Table 1). Equine butyrophilin was also strongly stained by the Schiff reagent after oxidation of carbohydrate chains, suggesting that butyrophilin from mare milk is a highly glycosylated protein (data not shown). Interestingly, molecular weights deduced from full-length amino acid sequences of cow (UniprotKB \# P18892), goat (UniprotKB \# A3EY52), and mare (Ensembl database ENSECAP00000015692) butyrophilin are comparable (about $59 \mathrm{kDa}$ ). Thus, the different apparent molecular weights by SDS-PAGE observed across species for butyrophilin are likely due to differences in carbohydrate contents. Accordingly, an additional putative $N$-glycosylation site can be outlined for equine butyrophilin, which can account for the higher molecular weight observed in 
Table 1. Identification of pony mare milk fat globule membrane proteins from SDS-PAGE by peptide mass fingerprinting matrix-assisted laser desorption/ionization-time of flight (MALDI-TOF) or tandem mass spectrometry (MS/MS) analysis

Band Protein name Molecular Identification Peptide

Peptide sequence ${ }^{2}$

a Xanthine dehydrogenase/oxida [A9YL93; Oryctolagus cuniculus (rabbit)]

mass $(\mathrm{kDa})$ method Peptide sequence ${ }^{2}$

position

NADPETTLLAYLR

\section{LGLSGTKLGCGEGGCGACTVMLSK}

$34-57$ LHPVQER

98-104

LVVGNTEIGIEMK

$257-269$

GVLEQLR

MDHTFFPGYR

$329-335$

EGEFFSAFK

DPPANVQLFQEVPK

$38.5-394$

ITYEDLPAIITIEDAIK

GEAGEMELFVSTQNTMK

$414-422$

$553-566$

688-704

DEDMLITGGR

HPFLAR

$756-772$

831-840

TNLPSNTAFR

841-846

EGDLTHFNQK

MVQVASR

RLEPFK

IPAFGSIPIEFR

$904-913$

950-959

SQHTDYNTKPLFR

[A3EY52; Capra hircus (goat)]

EGREQEGE

LLEELK

.

$1,101-1,106$

$1,230-1,241$

$1,284-1,296$

79-92

116-123

ATLHAVDVTLDPDTAHPHLFLYEDSK

QKLPEKPER

FDSWPCVMGR

EAFTSGR

HYWEVEVGDR

Sperm-membrane associated protein P47 $41 \quad$ MS/MS

TPLPLAGPPR

C Sperm-membrane associated prote
[O77718; Equus caballus (horse)

GPCFPNPCQNDGECHVIDDSHR

$332-340$

$341-350$

351-357

358-367

$411-420$

$46-67$

GDVFTQYICSCPR

GYTGTHCETTC

TGIVNAWTASNYDKNPWIQVNLMR

VTGVVTQGASRGGTAEYLK

68-80

$81-91$

132-155

TFKVAYSVDGR

159-177

FQFIRDAGDSK

178-188

190-200

VFVGNVDNSGLKVNMFDVPLEVQYVR 203-228

LVPVACHHGCTLR

229-241

FELLGCEVNGCAEPLGLEDNSIPDR

FELLGCEVNAGCAEPLGLEDNSIPDR GCAEPLGLEDNSIPDR

AGCAEPLGLEDNSIPDR

242-267

$251-266$

251-267

QITASSTYR

$267-275$

TWGLNAFSWYPFYAR

276-290

GLNAFSWYPFYAR

$278-290$

QGKFNAWTAQSNSASEWLQVDLGSQK

294-319

QVTGVITQGAR

DFGHIQYVAAYK

$320-330$

$331-342$

VSHSNDGANWTEYRDQR 343-359

PGNLDNNSHKK

KNMFETPFLAR

ILPVAWHNR

ITLRVELLGC

[O77718; Equus caballus (horse)]

GPCFPNPCQNDGECHVIDDSHR

377-387

391-399

400-409

$46-67$

GDVFTQYICSCPR

GYTGTHCETTC

$68-80$

$81-91$

TGIVNAWTASNYDKNPWIQVNLMR

132-155

$157-169$

RVTGVVTQGASR

159-177

170-180

GGTAEYLKTFK

$178-188$

TFKVAYSVDGR

203-228

LVPVACHHGCTLR

$229-241$

Continued 
Table 1 (Continued). Identification of pony mare milk fat globule membrane proteins from SDS-PAGE by peptide mass fingerprinting matrixassisted laser desorption/ionization-time of flight (MALDI-TOF) or tandem mass spectrometry (MS/MS) analysis

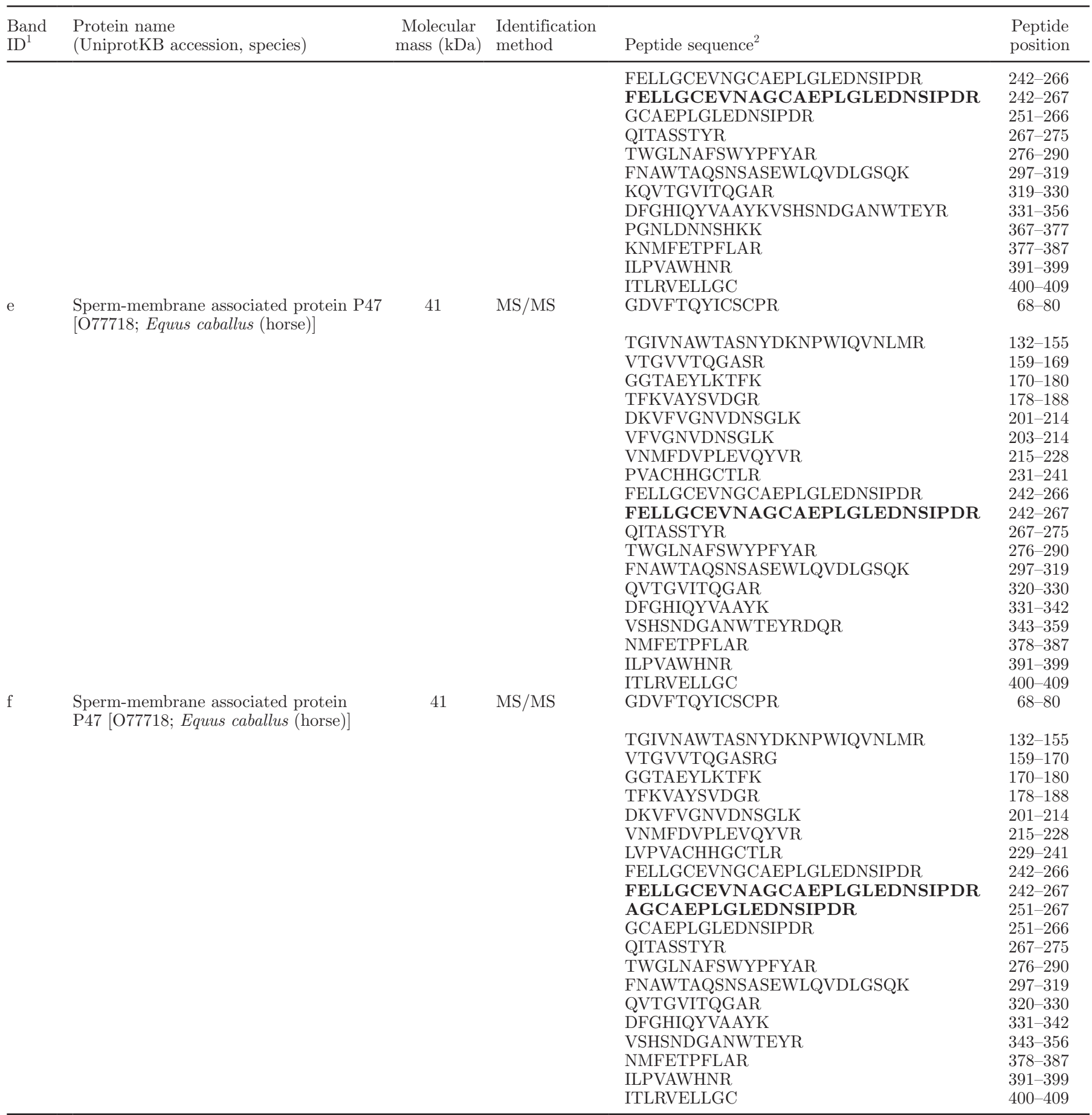

${ }^{1}$ Letters a to f refer to the bands in lane 1 (mare MFGM proteins) of Figure 1. Partial coding sequence.

${ }^{2}$ Peptides resulting from the tryptic digestion of the alternative equine lactadherin protein (GenBank AEC32944, our data) are indicated in bold.

SDS-PAGE for butyrophilin from mare milk compared with its bovine or caprine counterparts. Figure 2 shows the alignment of amino acid sequences of butyrophilin from cow, goat, and mare milk. Butyrophilin from mare milk displays only $85 \%$ sequence identity, whereas the sequence from goat is highly related (97\% similarity) to its bovine counterpart. Accordingly, butyrophilin from mare milk is not recognized by antibodies raised against bovine butyrophilin, in contrast to butyrophilin from goat milk (Cebo et al., 2010 and data not shown). 
BtaP18892

ChIA3EY52

Eca15692

BtaP18892

ChIA3EY52

Eca15692

BtaP18892

ChIA3EY52

Eca15692

BtaP18892

ChIA3EY52

Eca15692

BtaP18892

ChIA3EY52

Eca15692

BtaP18892

ChIA3EY52

Eca15692

BtaP18892

ChIA3EY52

Eca15692

BtaP18892

ChIA3EY52

Eca15692

BtaP18892

ChIA3EY52

Eca15692
MAVFPNSCLAGCLLIFILLQLPKLDSAPFDVIGPQEPILAVVGEDAELPCRLSPNVSAKG MAVFPNSCLLGCLLIFIALQLPKLDSAPFDVIGPPEP I LAMLGEDAELPCRLSPNVSAKG MAGFPNSCLITLIFLW----LPTLDSAHFDVIGPPEPILAIVGEDAELPCHLS PNVSAED

\begin{abstract}
MELRWFREKVSPAVFVSREGQEQEGEEMAEYRGRVSLVEDHIAEGSVAVRIQEVKASDDG MELRWFREKVSPAVFVSREGREQEGEEMAEYRGRVSLVEDHIAEGSVAVRIQDVKASDDG MELRWFRKKVSPAVFVHREGREQEGEQMAEYRGRATLVKTNVTAGRVAVKIHGVKASDDG

Ig-like V-type 2

EYRCFFRQDENYEEAIVHLKVAALGSDPHISMKVQESGE IQLECTSVGWYPEPQVQWRTH EYRCFFRQDENYEEAIVHLKVAALGSDPHINMKVQESGEILLECTSVGWHPEPQVQWRTH EYRCFFRQEDSFEEAIVQLKVAALGSDPH I HMEVQESGE IWLQCTSVGWYPEPQVQWRTP
\end{abstract}

RGEEFPSMSESRNPDEEGLFTVRASVI IRDSSMKNVSCCIRNLLLGQEKEVEVSIPASFF EGEEFPSMSESRTPDEEGLFTVRASVI IRDTSMKNVSCCIRNLLLGQEKEVEIS I PASFF KGEKFPSMSEARNPDEEGLFTVTASVVIRDTSMKNVSCCIQNLLLGQEKEGEIS I PAPFF

transmembrane

B30.2/SPRY

PRLTPWMVAVAVILVVLGLLTIGS IFFTWRLYKERSRQRRNEFSSKEKLLEELKWKRATL PRLTPWMVAVAV ILVVLGLLT I GS I FFTWRLYKERSRQRRNE FSSKEKLLEELKWKKATL PRLTPWMVAVAVVLMVLALLT IGS IFFTWRLYKERSRQRKDTFSSKEKLLEELKWKKATL

HAVDVTLDPDTAHPHLFLYEDSKSVRLEDSRQKLPEKPERFDSWPCVMGREAFTSGRHYW HAVDVTLDPDTAHPHLFLYEDSKSVRLEDSRQKLPEKPERFDSWPCVMGREAFTSGRHYW HAVDVTLDPDTAHPHLFLYEDSKSVRLEDARQKLPEKPEREDSWPCVLGREAFTSGRHYW

EVEVGDRTDWAIGVCRENVMKKGFDPMTPENGFWAVELYGNGYWALTPLRTPLPLAGPPR EVEVGDRTDWAIGVCRENVMKKGFDPMTPENGFWAVELYGNGYWALTPLRTPLPLAGPPR EVEVGDRTDWAIGVCRENVMKKGFDPMTPENGFWAVELYGNGYWALTPLRTPLPLAGPPR

RVGVFLDYESGDIFFYNMTDGSHIYTFSKASFSGPLRPFFCLWSCGKKPLTICPVTDGLE RVGVFLDYESGDIFFYNMTDGSHIYTFSKASFSGPLRPFFCLWSCGKKPLTICPITDGLE RVGIFLDYESGDISFYNMTDGSHIYTFPNTSFSGPLRPFFCLWSCGKKPLTICPITDGPE

GVMVVADAKDISKEI PLSPMGEDSASGDIETLHSKLI PLQPSQGVP GVMVVADAKDISKEI PLSPMGEDSASGDIETLHSKLIPLQPSQGVP EVLVVANGKDLSKEI PLSPMGEDSASGDTDTLHSKLIPTQTSQGAP

Figure 2. Alignment of the AA sequences of bovine (UniprotKB \#P18892), caprine (UniprotKB \#A3EY52), and equine (Ensembl database ENSECAP00000015692) butyrophilin. Functional domains of bovine butyrophilin are specified (Ig-like V-type 1, Ig-like V-type 2, transmembrane, and B30.2/SPRY). Predicted $N$-glycosylation sites are indicated in bold (N). Note the presence of an additional putative $N$-glycosylation site in the first immunoglobulin-like domain of equine butyrophilin. Bta = Bos taurus; Chi = Capra hircus; Eca = Equus caballus.

However, when the B30.2 domain (AA 285 to 479 in bovine butyrophilin) was considered, the alignment scores with bovine butyrophilin were 95 and $99 \%$ for equine and caprine butyrophilin, respectively, underlining the biological function recently attributed to this domain (Jeong et al., 2009).

\section{Two Splice Variants Are Shown for Equine Lactadherin}

Additional experiments were designed to determine if the different lactadherin bands observed in SDS-PAGE after Coomassie staining resulted from posttranscriptional (i.e., differential splicing) or posttranslational (i.e., differential glycosylation) events (or both). We first searched for splice variants for equine lactadherin.

The sequence for lactadherin transcript in EquCab2 assembly (Wade et al., 2009) was 93\% homologous to a 1,089-bp mRNA sequence (UniProtKB accession no. O77718) identified in the equine male genital tract, orthologous to a protein first characterized in the pig genital tract and spermatozoa (Petrunkina et al., 2003). Eight exons covering a 1,433-bp sequence 
A

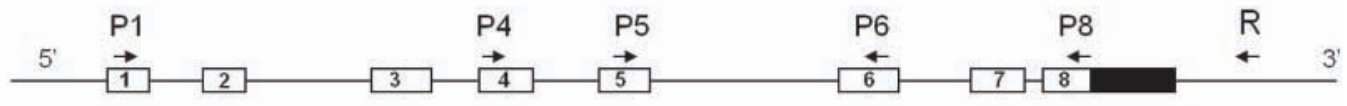

B

C
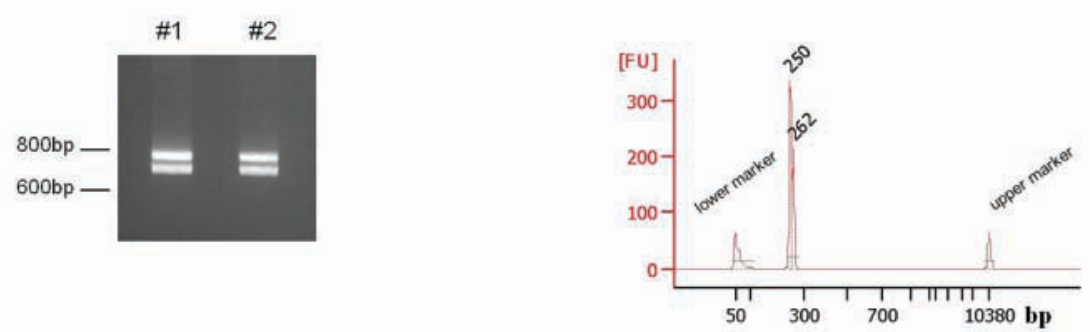

D

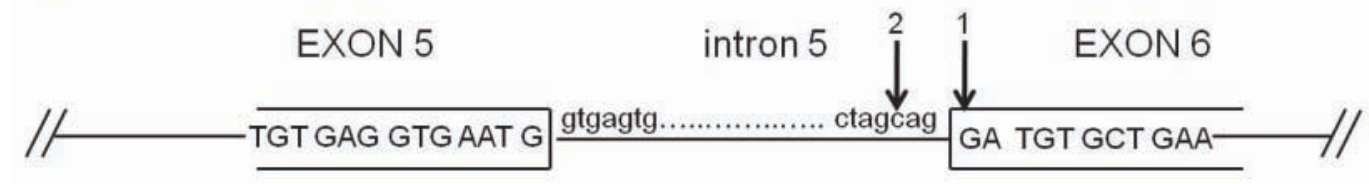

Isoform \#1 C E V N

Isoform \# 2 C E V N
G C A E

A G C A E

Figure 3. Analysis of equine lactadherin transcripts. (A) Schematic representation of the sperm-membrane associated protein P47 gene. Exons are indicated as numbered boxes. The 3 '-untranslated region is shaded. Positions of primers used for selective amplification of lactadherin mRNA regions are indicated. (B) Agarose gel electrophoresis of horse lactadherin PCR P4/P8 products. For each individual, 2 bands are clearly visualized. (C) Electropherograms of P5/P6 PCR products using Agilent 2100 Bioanalyzer (Agilent Technologies, Massy, France). Note that 2 peaks are visualized after PCR amplification. (D) Schematic representation of cryptic splicing event occurring on equine lactadherin transcript. Sequences located at the end of exon 5 and at the beginning of exon 6 are shown. The 2 splice acceptor sites are indicated by arrows. A cryptic splice site located at the end of intron 5 leads to the formation of a GCA nucleotide triplet encoding an Ala residue (A), followed by a GGA triplet encoding a Gly $(\mathrm{G})$ residue. Resulting amino acid sequences are indicated. Alternative sequence for lactadherin transcript (minor variant) is available in GenBank under accession number JF681042. Color version available in the online PDF.

were assigned for the lactadherin transcript from Equus caballus. Primers were thus designed to amplify specific regions of the horse lactadherin transcript (Figure $3 \mathrm{~A})$. The primer pair $\mathrm{P} 1 / \mathrm{P} 8$ amplifies horse lactadherin transcripts from exon 1 to exon 8 (PCR product size: 1,139 bp), whereas the $\mathrm{P} 4 / \mathrm{P} 8, \mathrm{P} 5 / \mathrm{P} 6$, and $\mathrm{P} 1 / \mathrm{R}$ primer pairs produce 704-, 237-, and 1,434-bp PCR fragments, respectively. Interestingly, 2 PCR products were amplified from milk fat globule-extracted mRNA regardless of the primer pair used for PCR amplification (Figure 3B and 3C, and data not shown), suggesting that alternative splicing events occur in lactadherin primary transcripts from equine mammary gland. Such a posttranscriptional event has been previously shown for a lactadherin transcript isolated from the equine male genital tract (UniprotKB accession no. O77718|
Sperm-membrane associated protein P47). Indeed, the AA sequence RFELLGCEVNGCAEPLGLEDNSI, corresponding to the end of exon 5 and the beginning of exon 6 of equine gene coding for lactadherin, was deleted in the testis-specific transcript (see Figure 5). To clarify this, we cloned PCR products resulting from selective amplification of the region spanning from exon 4 to exon 8 of lactadherin transcripts. Clone sequencing revealed the existence of $2 \mathrm{mRNA}$ variants for lactadherin in the equine mammary gland. We demonstrated that a cryptic splice site located at the end of intron 5 in the lactadherin primary transcript led to the formation of a GCA nucleotide triplet encoding an Ala (A) residue, followed by a GGA triplet encoding a Gly (G) residue in the minor lactadherin transcript, which was consequently 1 AA longer than the canonical messenger 
A

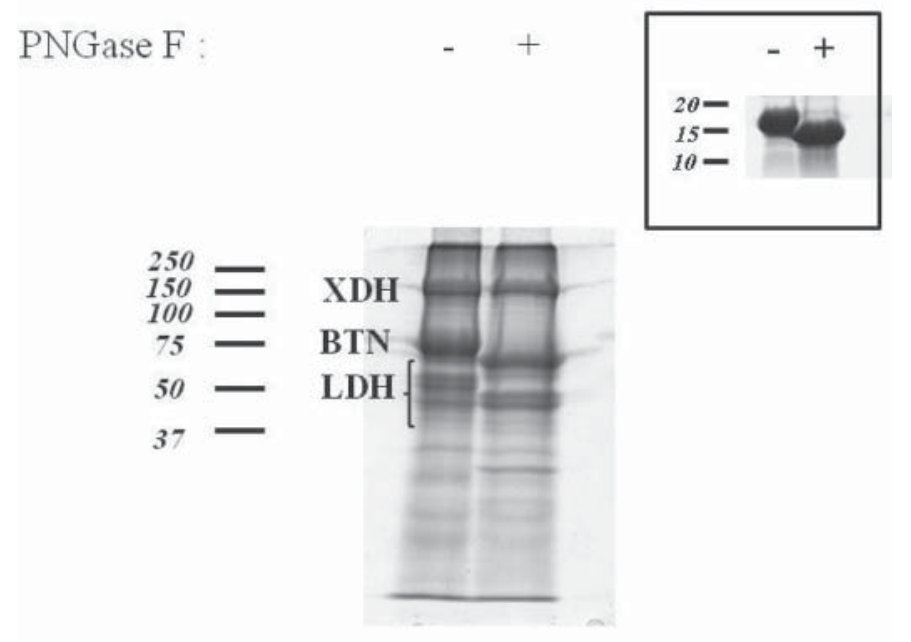

B

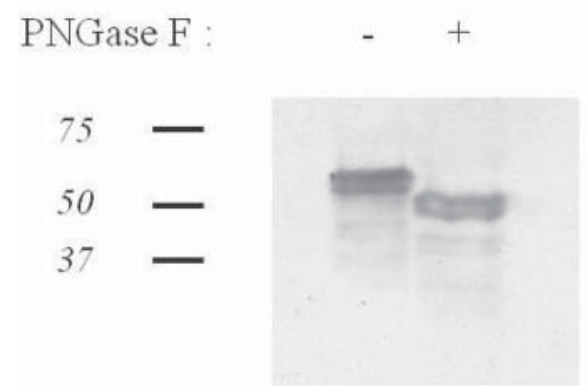

Figure 4. Peptide $N$-glycosidase (PNGase F) digestion of milk fat globule membrane proteins from mare milk. (A) PNGase F digestion was monitored by $10 \%$ SDS-PAGE followed by staining with Biosafe. Note that, among major MFGM proteins from mare milk, butyrophilin (BTN) and lactadherin (LDH) proteins were sensitive to enzyme treatment, whereas xanthine oxidase $(\mathrm{XDH})$ migration in SDS-PAGE was not affected by PNGAse F treatment. Inset: Positive control for enzymatic $N$-deglycosylation. A shift in ribonuclease B mobility is observed after removal of $N$-linked glycans. Molecular weights are 17 and $14 \mathrm{kDa}$ for the $N$-glycosylated and the full- $N$-deglycosylated protein, respectively. (B) PNGase F digestion of MFGM proteins from mare milk followed by immunoblotting with antibodies against bovine lactadherin.

(Figure 3D and Figure 5). This phenomenon can be explained by a competition between adjacent AG pairs at the $3^{\prime}$ splice site. Indeed, the nucleotide preceding the AG has a prominent influence upon competition between closely spaced AG pairs (Smith et al., 1993). In equine lactadherin, the CAG triplet at the end of intron 5 is immediately preceded by a TAG triplet, which is relatively equivalent in terms of 3 ' splice site preference. This may explain the existence of both transcript variants for equine lactadherin. Such errors of the splicing machinery have previously been shown in the horse for $\alpha_{\mathrm{S}_{1}} \mathrm{CN}$ (Matéos et al., 2009). Indeed, for each isoform of equine $\alpha_{\mathrm{S}_{1}} \mathrm{CN}$ identified (full length $\alpha_{\mathrm{S} 1}$-CN and $\alpha_{\mathrm{S}^{-}} \mathrm{CN}^{\Delta 7}, \alpha_{\mathrm{S}^{-}} \mathrm{CN}^{\Delta 14}, \alpha_{\mathrm{S}^{-}} \mathrm{CN}^{\Delta 7,14}$ that resulted, respectively, from skipping exon 7 , exon 14 , or both), a shorter isoform lacking a glutamine $(\mathrm{N})$ residue was characterized. As observed for equine lactadherin, the loss of a glutamine residue in equine $\alpha_{\mathrm{S} 1}-\mathrm{CN}$ could be explained by a splicing error by the spliceosome. The codon CAG (encoding a glutamine residue) at the beginning of an exon could be confused with the AG splice acceptor site of the adjacent intron (Martin et al., 2002; Matéos et al., 2009). Interestingly, in the case of equine lactadherin, this cryptic splicing event led to the disruption of a putative Asn-Gly-Cys $\mathrm{N}$-glycosylation site (Figure 5). This atypical $N$-glycosylation site, which is conserved in the horse species, is occupied with glycans in human lactadherin (Picariello et al., 2008). However, tryptic peptides (e.g., FELLGCEVNGCAEPLGLEDNSIPDR/FELLGCEVNAGCAEPLGLEDNSIPDR) corresponding to both lactadherin variants (designated as Eca16644, ENS00000016644, in the Ensembl database, and as EcaF5CEP2, UniprotKB accession no. F5CEP2, our data) in Figure 5 were detected in all lactadherin chains (Table 1). These data strongly suggest that the alternative splicing of lactadherin mRNA in the horse species (and therefore, the glycosylation status of the atypical $\mathrm{N}$-glycosylation site) is not responsible for the different molecular weights observed in SDS-PAGE for equine lactadherins.

\section{Both N-Terminal and C-Terminal Regions of the Protein Are Present on the Different Isoforms Observed for Equine Lactadherin in SDS-PAGE}

Another possibility was that the different isoforms observed in SDS-PAGE for equine lactadherin could be truncated versions of the lactadherin integral protein, as previously demonstrated for human lactadherin (Giuffrida et al., 1998). We thus performed $N$-terminal sequencing experiments on lactadherin isoforms. N-Terminal microsequencing results showed that the first AA for equine lactadherin were identical to an ASGD (AlaSer-Gly-Asp) sequence (data not shown). Our experimental data do not correspond to the N-terminal amino acid sequence provided by automatic annotation of the Equus caballus genome (ENSECAP00000016644). Bovine (Ensembl accession no. ENSBTAP00000004272), caprine (GenBank accession no. GQ344829), and swine (ENSSSCP00000002007) lactadherin are encoded by 9 exons, the first encoding mostly the signal peptide, whereas only 8 exons are assigned to equine lactadherin (Ensembl accession no. ENSECAP00000016644). Multi-species alignment of AA sequences for lactadherin clearly showed that the signal peptide is missing in the equine lactadherin, suggesting that the sequence of the equine lactadherin gene is actually incomplete (data not shown). On the other hand, Aoki et al. (1994) 
BtaQ95114
ChiC7FDJ1
HsaQ08431
Eca16644
EcaF5CEP2
EcaO77718

BtaQ95114
ChiC7FDJ1
HsaQ08431
Eca16644
EcaF5CEP2
EcaO77718

BtaQ95114

ChIC7FDJ1

HsaQ08431

Eca16644

ECaF5CEP2

Eca077718

BtaQ95114

ChIC7FDJ1

HsaQ08431

Eca16644

ECaF5CEP2

Eca077718

BtaQ95114 ChiC7FDJ1 HsaQ08431 Eca16644 ECaF5CEP2 EcaO 77718

BtaQ95114 ChiC7FDJ1 HsaQ08431 Eca16644 ECaF5CEP2 EcaO77718

BtaQ95114 ChiC7FDJ1 HsaQ08431 Eca16644 ECaF5CEP2 EcaO 77718

BtaQ95114 ChiC7FDJ1 HsaQ08431 Eca16644

ECaF5CEP2

EcaO 77718

\section{EGF-like 1}

MPCPRLLA----ALFCSSGLFAASGDFCDSSLCLHGGTCLLNEDRTPPFYCLCPEGFTGL MPSPRLLAALCGALFCASGLFAFSGDLCDSSQCLHGGTCLLNEEKTPPFYCLCPEGFTGL

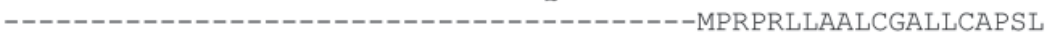
-.-n ---------------------------- GRP---PFYCLCPEGFTGL $-7$ EGF-like 2

LCNETEHGPCFPNPCHNDAECQVTDDSHRGDVFIQYICKCPLGYVGIHCETTCTSPLGMQ LCNETEYGPCFPNPCHNDAECOVT-DTLRGDVFTHYICKCPLGYVGTHCESTCTSPLGMO LV---ALDICSKNPCHNGGLCEE ISQEVRGDVFPSYTCTCLKGYAGNHCETKCVEPLGME ICNETEKGPCFPNPCQNDGECHVIDDSHRGDVFTQYICSCPRGYTGTHCETTCAMPLGME ICNETEKGPCFPNPCQNDGECHVIDDSHRGDVFTQYICSCPRGYTGTHCETTCAMPLGME ICNETEKGPCFPNPCQNDGECHVIDDSHRGDVFTQYICSCPRGYTGTHCETTCAMPLGME

\section{F5/8 type C 1}

TGAIADSQISASSMHLGFMGLQRWAPELARLHQTGIVNAWTSGNYDKNPWIQVNLMRKMW TGAIADSQISASSMHLGFMGLQRWAPELARLYQTGIVNAWTSSNYDKNPWIQVNLLRKMW NGNIANSQIAASSVRVTFLGLQHWVPELARLNRAGMVNAWTPSSNDDNPWIQVNLLRRMW TGAIADAQI SASSVYFGFMGLQRWVPELARLHRTGIVNAWTASNYDKNPWIQVNLMRKMR TGAIADAOI SASSVYFGFMGLORWVPELARLHRTGIVNAWTASNYDKNPWIOVNLMRKMR TGAIADAQISASSVYFGFMGLQRWVPELARLHRTGIVNAWTASNYDKNPWIQVNLMRKMR

VTGVVTQGASRAGSAEYLKTEKVAYSTDGRQFQFIQVAGRSGDKIFIGNVNNSGLKINLF VTGVVTQGASRAGSAEYVKTFKVAYSNDGHQFQFIQAAGQLGEKVR----NNSGLKINLF VTGVVTQGASRLASHEYLKAFKVAYSLNGHEFDFIHDVN-KKHKEFVGNWNKNAVHVNLF VTGVVTQGASRGGTAEYLKTFKVAYSVDGRKFQFIRDAGDSKDKVFVGNVDNSGLKVNMF VTGVVTOGASRGGTAEYLKTFKVAYSVDGRKFOFIRDAGDSKDKVFVGNVDNSGLKVNMF VTGVVTQGASRGGTAEYLKTFKVAYSVDGRKFQFIRDAGDSKDKVFVGNVDNSGLKVNMF

F5/8 type C 2

DTPLETQYVRLVP I ICHRGCTLRFELLGCELNG-CTEPLGLKDNT I PNKQITASSYYKTW DSPLETQYVRLVPI ICRRGCTLRFELLGCELDG-CTEPLGLKDNTI PNKQITASSYYKTW ETPVEAQYVRLYPTSCHTACTLRFELLGCELNG-CANPLGLKNNSIPDKQITASSSYKTW DVPLEVQYVRLVPVACHHGCTLRFELLGCEVNG-CAEPLGLEDNS I PDRQITASSTYRTW DVPLEVQYVRLVPVACHHGCTLRFELLGCEVNAGCAEPLGLEDNS I PDRQITASSTYRTW DVPLEVTYVRLVPLACHHGCTR-----------------------PDRQITASSTYRTR

GLSAFSWFPYYARLDNQGKFNAWTAQTNSASEWLQIDLGSQKRVTGI ITQGARDFGHIQY GLSAFSWFPYYARLDNWGKFNAWTAQTNSASEWLQIDLGSQKRVTGIITQGARDFGHIQY GLHLFSWNPSYARLDKQGNFNAWVAGSYGNDQWLQVDLGSSKEVTGI ITQGARNFGSVQF GLNAFSWYPFYARLDKOGKFNAWTAQSNSASEWLQVDLGSOKQVTGVITQGARDFGHIQY GLNAFSWYPFYARLDKQGKFNAWTAQSNSASEWLQVDLGSQKQVTGVITQGARDFGHIQY GLNAFSWYPFYARLDKQGKFNAWTAQSNSASEWLQDDLGSQKEVTGVITQGARDFGHIQY

VAAYRVAYGDDGVTWTEYKDPGASESKIFPGNMDNNSHKKNIFETPFQARFVRIQPVAWH VAAYRVAYSDDGVTWTEYKDPETSKSKIFPGNMDNNSHKKNIFEVPFOARFVRIQPVAWH VASYKVAYSNDSANWTEYQDPRTGSSKIFPGNWDNHSHKKNLFETPILARYVRILPVAWH VAAYKVSHSNDGANWTEYRDQRAADSKIFPGNLDNNSHKKNMFETPFLARFVRILPVAWH VAAYKVSHSNDGANWTEYRDQRAADSKIFPGNLDNNSHKKNMFETPFLARFVRILPVAWH VDAYKVSHSNDGANWTEYRDQRAADSKIFLGNLDNNSHKKNMFETPFLARFVRILPVAWH

Figure 5. Alignment of the amino acid sequences of bovine (UniprotKB \#Q95114), human (UniprotKB \#Q08431), and equine [Ensembl no. ENSECAP00000016644, F5CEP2 (mammary gland, our data), and UniprotKB \#O77718 (testis)] lactadherin. Functional domains of bovine lactadherin protein are indicated (EGF-like 1, EGF-like 2, F5/8 type C 1, and F5/8 type C2). Glycosylation sites are highlighted for bovine PAS $6(\boldsymbol{\nabla})$ and PAS $7(\boldsymbol{\square})$, according to Hvarregaard et al. (1996). N-Glycosylation sites for human lactadherin (Picariello et al., 2008) are indicated in bold. Bta = Bos taurus; Chi = Capra hircus; Eca = Equus caballus; Hsa = Homo sapiens. Superscript 1 indicates partial coding sequence. 
highlighted the same N-terminal ASGD sequence for bovine PAS 6/7 glycoproteins. In addition, LC-MS/ MS analysis of tryptic peptides after in-gel digestion of the 4 bands corresponding to equine lactadherin (Figure 1 and Table 1) revealed the presence of both N-terminal and C-terminal peptides. This finding ruled out the possibility of truncation of lactadherin from mare milk during posttranslational events, as previously demonstrated for lactadherin from human milk (e.g., the peptide GDVFTQYICSCPR, at position 68-80 of equine lactadherin, and the semi-tryptic peptide ILTRVELLGC located at the C-terminal end of lactadherin; Giuffrida et al., 1998; Cavaletto et al., 1999).

\section{Differential Glycosylation Is Mainly Responsible for the Complexity of Lactadherin from Mare Milk}

Finally, we wondered whether the existence of 4 lactadherin isoforms in the horse species was due to differential glycosylation of a single polypeptide backbone, as shown in the bovine species (Hvarregaard et al., 1996).

$N$-Deglycosylation experiments on MFGM proteins from mare milk revealed that the 60 - and $57-\mathrm{kDa}$ lactadherin isoforms were sensitive to PNGase $\mathrm{F}$ treatment (Figure 4A and B), suggesting that $N$-glycans were actually present on these isoforms. Remarkably, although the deglycosylation step was assumed to be complete (Figure 4A, inset), the 2 upper isoforms (57 and 60 $\mathrm{kDa}$ bands) were not resolved in a single band after PGNase F digestion of MFGM samples and Western blotting with specific antibodies (Figure 4B), as previously observed for bovine lactadherin (Hvarregaard et al., 1996). This strongly suggests that differential $\mathrm{N}$ glycosylation is not solely responsible for the different isoforms $(60,57,48$, and $45 \mathrm{kDa})$ observed for equine lactadherin in SDS-PAGE.

Consequently, differences between molecular weights of lactadherin isoforms may be also explained by differential $O$-glycosylation of the protein, as demonstrated in the bovine (Hvarregaard et al., 1996). Indeed, carbohydrate structures highly similar to the tetrasaccharide NeuNAc $(\alpha 2,6) \operatorname{Gal}(\beta 1,4) \operatorname{GlcNAc}(\beta 1,3)$ Fuc $(\alpha 1-\mathrm{O})$ Ser present in the first epidermal growth factor domain of human factor IX were identified at positions Ser9 and Thr16 of PAS6 and PAS7, respectively (Hvarregaard et al., 1996). Taken together, our data favor the hypothesis that the $60-\mathrm{kDa}$ lactadherin isoform is $N$ - and $O$-glycosylated, whereas the 57 and $48 \mathrm{kDa}$ lactadherin isoforms harbor only $\mathrm{N}$ - or $\mathrm{O}$-glycans, respectively, the latter chain (45 kDa) bearing no glycans. Accordingly, the molecular weight of the $45-\mathrm{kDa}$ isoform corresponds roughly to that deduced from the AA sequence of lacta- dherin (Ensembl accession no. ENSECAP00000016644). We are now trying to purify the different isoforms of lactadherin from pony mare milk to describe thoroughly the carbohydrate composition of lactadherin isoforms described in this study.

\section{DISCUSSION}

Milk fat globule-epidermal growth factor (MFG-E8) or lactadherin was formerly known as PAS 6/7 glycoprotein in bovine milk, due to its strong staining with the periodic acid-Schiff (PAS) reagent. Common features of lactadherin are the presence of 2 epidermal growth factor (EGF)-like domains in the $N$-terminal part of the protein (only one EGF-like domain in human lactadherin) with an Arg-Gly-Asp (RGD) sequence in the second EGF-like domain, and of $2 \mathrm{C}$-terminal domains called F5/8 type $\mathrm{C}$ (or $\mathrm{C} 1 / \mathrm{C} 2$-like domains), which are also present in coagulation factors V and VIII (Stubbs et al., 1990; Larocca et al., 1991; Hvarregaard et al., 1996). Each domain is responsible for distinct biological activities of lactadherin. Lactadherin is involved in cellular apoptosis events through its phosphatidylserinebinding motif (Shi and Gilbert, 2003; Shi et al., 2004), whereas the RGD sequence mediates cellular adhesion mechanisms through binding to $\alpha_{\mathrm{v}} \beta_{3 / 5}$ integrins (Taylor et al., 1997). Fat globules from mare colostrum can stimulate proliferation of human fibroblasts in vitro (Zava et al., 2009). Those authors suggested that lactadherin, through its EGF-like domains, may be responsible for the proliferative properties of mare colostrum displayed in the study. Direct evidence for antiviral properties of lactadherin from human milk has also been demonstrated (Newburg et al., 1998; Kvistgaard et al., 2004), therefore presenting this protein as a potential nutraceutical (Spitsberg, 2005). In fact, lactadherin is involved in a wide range of biological functions, including apoptosis, mammary gland development and involution, sperm-egg interaction, angiogenesis, and maintenance of the intestinal epithelium (Raymond et al., 2009). Moreover, this glycoprotein has been shown to be involved in numerous pathologies, mainly of inflammatory origin (Ait-Oufella et al., 2007; Boddaert et al., 2007). Lactadherin is also overexpressed in mammary tumors and this glycoprotein has been recently involved in bladder tumor development (Larocca et al., 1991; Sugano et al., 2011).

Multiple forms of lactadherin have been characterized across species. In cattle, 2 glycoprotein components (PAS 6/7) resulting from differential glycosylation of a common polypeptide core have been described (Hvarregaard et al., 1996). In mice, a long lactationdependent variant has been identified in the mammary gland. This tissue-specific variant contains an addi- 
tional exon encoding a Pro/Thr-rich domain bearing multiple $O$-linked glycan chains potentially involved in the secretion process (Oshima et al., 1999). In human milk, 2 proteins of 50 and $30 \mathrm{kDa}$ have been characterized. The $30-\mathrm{kDa}$ protein is a truncated form of the fulllength protein, which consists of the C-terminal factor V/VIII domain (Giuffrida et al., 1998). In addition, a 50-AA peptide called medin has been purified from human aortic smooth cells (Häggqvist et al., 1999). We have recently shown that lactadherin from goat milk appears as a single polypeptide chain, whereas bovine lactadherin consists of 2 polypeptide chains, in accordance to literature data (Hvarregaard et al., 1996; Cebo et al., 2010).

Posttranscriptional modifications have been shown for lactadherin across species. A splice variant lacking 52 AA residues located in the first factor V-VIII C domain has been detected in cattle (Hvarregaard et al., 1996). Here, we showed an alternative use of a cryptic splice site located at the end of intron 5 of the equine lactadherin encoding gene. This event results in the occurrence of an additional Ala (A) residue in the protein, disrupting the putative atypical $N$-glycosylation site (VNGC/VNAGC), described in human lactadherin (Picariello et al., 2008). Interestingly, aberrant splicing of the lactadherin gene has been reported in human systemic lupus erythematosus, highlighting the need to better characterize splicing events occurring on lactadherin transcripts (Yamaguchi et al., 2010).

However, differences in apparent molecular weight in SDS-PAGE for lactadherin through species are mostly due to posttranslational events on the polypeptide backbone. Differential glycosylation is responsible for the existence of 2 glycoprotein variants in cattle (PAS 6/7). According to literature, PAS-6 is $N$-glycosylated at Asn41 and Asn209, whereas PAS-7 is N-glycosylated only at Asn41 (Hvarregaard et al., 1996). Lactadherin from goat milk appears as a single glycoprotein in SDS-PAGE (Cebo et al., 2010). Accordingly, using predictive software for $\mathrm{N}$-glycosylation sites with the AA sequence for lactadherin from goat milk (ACU32797.2, GenBank database), a single $N$-glycosylation site can be outlined for caprine lactadherin, whereas $2 \mathrm{~N}$ glycosylation sites are predicted for bovine lactadherin (Q95114, UniprotKB database), in accordance with experimental data (Hvarregaard et al., 1996). In addition, 2 lactadherin isoforms are present in camel milk [B. Saadaoui (Faculté des Sciences de Gabès, Tunisia), C. Henry, T. Khorchani (Institut des Régions Arides. Medenine Tunisia), M. Mars (Faculté des Sciences de Gabès,Tunisia), P. Martin, and C. Cebo, unpublished data]. Taken together, these data highlight the remarkable polymorphism of lactadherin across species, thus bringing into question the precise function of these different isoforms, if any, in the mammary gland. Additionally, because the different lactadherin isoforms arise mostly from differential $\mathrm{N}$-glycosylation of a single polypeptide chain, involvement of $\mathrm{N}$-glycans in the lactadherin biological function must be examined.

\section{ACKNOWLEDGMENTS}

We thank Guy Duchamp and Elodie Guettier (Unité Expérimentale de Physiologie animale de l'Orfrasière, Nouzilly, France), for providing us with the opportunity to collect mare milk samples. Jan Trige Rasmussen (Department of Molecular Biology, Aarhus University, Denmark) is warmly acknowledged for the gift of antilactadherin antibodies. Guy Miranda (INRA, Jouy-enJosas) is also acknowledged for invaluable discussions around milk proteins.

\section{REFERENCES}

Ait-Oufella, H., K. Kinugawa, J. Zoll, T. Simon, J. Boddaert, S. Heeneman, O. Blanc-Brude, V. Barateau, S. Potteaux, R. Merval, B. Esposito, E. Teissier, M. J. Daemen, G. Leseche, C. Boulanger, A. Tedgui, and Z. Mallat. 2007. Lactadherin deficiency leads to apoptotic cell accumulation and accelerated atherosclerosis in mice. Circulation 115:2168-2177.

Aoki, N., M. Ujita, H. Kuroda, M. Urabe, A. Noda, T. Adachil, R. Nakamura, and T. Matsuda. 1994. Immunologically cross-reactive $57 \mathrm{kDa}$ and $53 \mathrm{kDa}$ glycoprotein antigens of bovine milk fat globule membrane: Isoforms with different $N$-linked sugar chains and differential glycosylation at early stages of lactation. Biochim. Biophys. Acta 1200:227-234.

Barello, C., L. P. Garoffo, G. Montorfano, S. Zava, B. Berra, A. Conti, and M. G. Giuffrida. 2008. Analysis of major proteins and fat fractions associated with mare's milk fat globules. Mol. Nutr. Food Res. 52:1448-1456.

Boddaert, J., K. Kinugawa, J. Lambert, F. Boukhtouche, J. Zoll, R. Merval, O. Blanc-Brude, D. Mann, C. Berr, J. Vilar, B. Garabedian, N. Journiac, D. Charue, J. Silvestre, C. Duyckaerts, P. Amouyel, J. Mariani, A. Tedgui, and Z. Mallat. 2007. Evidence of a role for lactadherin in Alzheimer's disease. Am. J. Pathol. 170:921-929.

Businco, L., P. G. Giampietro, P. Lucenti, F. Lucaroni, C. Pini, G. Di Felice, P. Iacovacci, C. Curadi, and M. Orlandi. 2000. Allergenicity of mare's milk in children with cow's milk allergy. J. Allergy Clin. Immunol. 105:1031-1034.

Cavaletto, M., M. G. Giuffrida, C. Giunta, C. Vellano, C. Fabris, E. Bertino, J. Godovac-Zimmermann, and A. Conti. 1999. Multiple forms of lactadherin (breast antigen BA46) and butyrophilin are secreted into human milk as major components of milk fat globule membrane. J. Dairy Res. 66:295-301.

Cebo, C., H. Caillat, F. Bouvier, and P. Martin. 2010. Major proteins of the goat milk fat globule membrane. J. Dairy Sci. 93:868-876.

D'Ambrosio, C., S. Arena, A. M. Salzano, G. Renzone, L. Ledda, and A. Scaloni. 2008. A proteomic characterization of water buffalo milk fractions describing PTM of major species and the identification of minor components involved in nutrient delivery and defense against pathogens. Proteomics 8:3657-3666.

Fortunato, D., M. G. Giuffrida, M. Cavaletto, L. P. Garoffo, G. Dellavalle, L. Napolitano, C. Giunta, C. Fabris, E. Bertino, A. Coscia, and A. Conti. 2003. Structural proteome of human colostral fat globule membrane proteins. Proteomics 3:897-905.

Giuffrida, M. G., M. Cavaletto, C. Giunta, A. Conti, and J. GodovacZimmermann. 1998. Isolation and characterization of full and truncated forms of human breast carcinoma protein BA46 from human milk fat globule membranes. J. Protein Chem. 17:143-148. 
Häggqvist, B., J. Näslund, K. Sletten, G. T. Westermark, G. Mucchiano, L. O. Tjernberg, C. Nordstedt, U. Engström, and P. Westermark. 1999. Medin: An integral fragment of aortic smooth muscle cell-produced lactadherin forms the most common human amyloid. Proc. Natl. Acad. Sci. USA 96:8669-8674.

Hvarregaard, J., M. H. Andersen Lars Berglund, J. T. Rasmussen, and T. E. Petersen. 1996. Characterization of glycoprotein PAS-6/7 from membranes of bovine milk fat globules. Eur. J. Biochem. 240:628-636.

Jeong, J., A. U. Rao, J. Xu, S. L. Ogg, Y. Hathout, C. Fenselau, and I. H. Mather. 2009. The PRY/SPRY/B30.2 domain of butyrophilin 1A1 (BTN1A1) binds to xanthine oxidoreductase. J. Biol. Chem. 284:22444-22456.

Kvistgaard, A. S., L. T. Pallesen, C. F. Arias, S. Lopez, T. E. Petersen, C. W. Heegaard, and J. T. Rasmussen. 2004. Inhibitory effects of human and bovine milk constituents on rotavirus infections. J. Dairy Sci. 87:4088-4096.

Larocca, D., J. A. Peterson, R. Urrea, J. Kuniyoshi, A. M. Bistrain, and R. L. Ceriani. 1991. A Mr 46,000 human milk fat globule protein that is highly expressed in human breast tumors contains factor VIII-like domains. Cancer Res. 51:4994-4998.

Malacarne, M., F. Martuzzi, A. Summer, and P. Mariani. 2002. Protein and fat composition of mare's milk: Some nutritional remarks with reference to human and cow's milk. Int. Dairy J. 12:869-877.

Maningat, P. D., P. Sen, M. Rijnkels, A. L. Sunehag, D. L. Hadsell, M. Bray, and M. W. Haymond. 2009. Gene expression in the human mammary epithelium during lactation: The milk fat globule transcriptome. Physiol. Genomics 37:12-22.

Martin, P., M. Szymanowska, L. Zwierzchowski, and C. Leroux. 2002 The impact of genetic polymorphisms on the protein composition of ruminant milks. Reprod. Nutr. Dev. 42:433-459.

Matéos, A., J. Girardet, D. Mollé, C. Corbier, J. L. Gaillard, and L. Miclo. 2010. Identification of phosphorylation sites of equine betacasein isoforms. Rapid Commun. Mass Spectrom. 24:1533-1542.

Matéos, A., L. Miclo, D. Mollé, A. Dary, J. M. Girardet, and J. L. Gaillard. 2009. Equine $\alpha_{S 1}$-casein: Characterization of alternative splicing isoforms and determination of phosphorylation levels. J. Dairy Sci. 92:3604-3615.

Mather, I. H., and T. W. Keenan. 1998. Origin and secretion of milk lipids. J. Mammary Gland Biol. Neoplasia 3:259-273.

Miclo, L., J.-M. Girardet, A. S. Egito, D. Mollé, P. Martin, and J.-L. Gaillard. 2007. The primary structure of a low-Mr multiphosphorylated variant of $\beta$-casein in equine milk. Proteomics 7:1327-1335.

Miranda, G., M. Mahé, C. Leroux, and P. Martin. 2004. Proteomic tools to characterize the protein fraction of Equidae milk. Proteomics 4:2496-2509.

Newburg, D. S., J. A. Peterson, G. M. Ruiz-Palacios, D. O. Matson, A. L. Morrow, J. Shults, M. D. Guerrero, P. Chaturvedi, S. O. Newburg, C. D. Scallan, M. R. Taylor, R. L. Ceriani, and L. K. Pickering. 1998. Role of human-milk lactadherin in protection against symptomatic rotavirus infection. Lancet 351:1160-1164.

Oshima, K., N. Aoki, M. Negi, M. Kishi, K. Kitajima, and T. Matsuda. 1999. Lactation-dependent expression of an mRNA splice variant with an exon for a multiply o-glycosylated domain of mouse milk fat globule glycoprotein MFG-E8. Biochem. Biophys. Res. Commun. 254:522-528.

Petrunkina, A. M., A. Lakamp, M. Gentzel, M. Ekhlasi-Hundrieser, and E. Topfer-Petersen. 2003. Fate of lactadherin P47 during posttesticular maturation and capacitation of boar spermatozoa. Reproduction 125:377-387

Picariello, G., P. Ferranti, G. Mamone, P. Roepstorff, and F. Addeo. 2008. Identification of N-linked glycoproteins in human milk by hydrophilic interaction liquid chromatography and mass spectrometry. Proteomics 8:3833-3847.

Pisanu, S., S. Ghisaura, D. Pagnozzi, G. Biosa, A. Tanca, T. Roggio, S. Uzzau, and M. F. Addis. 2011. The sheep milk fat globule membrane proteome. J. Proteomics 74:350-358.
Quaranta, S., M. G. Giuffrida, M. Cavaletto, C. Giunta, J. GodovacZimmermann, B. Canas, C. Fabris, E. Bertino, M. Mombro, and A. Conti. 2001. Human proteome enhancement: High-recovery method and improved two-dimensional map of colostral fat globule membrane proteins. Electrophoresis 22:1810-1818.

Raymond, A., M. Ensslin, and B. Shur. 2009. SED1/MFG-E8: A bimotif protein that orchestrates diverse cellular interactions. J. Cell. Biochem. 106:957-966.

Reinhardt, T. A., and J. Lippolis. 2006. Bovine milk fat globule membrane proteome. J. Dairy Res. 73:406-416.

Shi, J. L., and G. E. Gilbert. 2003. Lactadherin inhibits enzyme complexes of blood coagulation by competing for phospholipid-binding sites. Blood 101:2628-2636.

Shi, J. L., C. W. Heegaard, J. T. Rasmussen, and G. E. Gilbert. 2004. Lactadherin binds selectively to membranes containing phosphatidyl-L-serine and increased curvature. Biochim. Biophys. Acta 1667:82-90.

Smith, C. W., T. T. Chu, and B. Nadal-Ginard. 1993. Scanning and competition between AGs are involved in 3 ' splice site selection in mammalian introns. Mol. Cell. Biol. 13:4939-4952.

Spitsberg, V. L. 2005. Bovine milk fat globule membrane as a potential nutraceutical. J. Dairy Sci. 88:2289-2294.

Stubbs, J. D., C. Lekutis, K. L. Singer, A. Bui, D. Yuzuki, U. Srinivasan, and G. Parry. 1990. cDNA cloning of a mouse mammary epithelial cell surface protein reveals the existence of epidermal growth factor-like domains linked to factor VIII-like sequences. Proc. Natl. Acad. Sci. USA 87:8417-8421.

Sugano, G., I. Bernard-Pierrot, M. Lae, C. Battail, Y. Allory, N. Stransky, S. Krumeich, M. L. Lepage, P. Maille, M. H. Donnadieu, C. C. Abbou, S. Benhamou, T. Lebret, X. Sastre-Garau, S. Amigorena, F. Radvanyi, and C. Thery. 2011. Milk fat globule-epidermal growth factor-factor VIII (MFGE8)/lactadherin promotes bladder tumor development. Oncogene 30:642-653.

Taylor, M., J. Couto, C. Scallan, R. Ceriani, and J. Peterson. 1997. Lactadherin (formerly BA46), a membrane-associated glycoprotein expressed in human milk and breast carcinomas, promotes Arg-Gly-Asp (RGD)-dependent cell adhesion. DNA Cell Biol. $16: 861-869$.

Wade, C. M., E. Giulotto, S. Sigurdsson, M. Zoli, S. Gnerre, F. Imsland, T. L. Lear, D. L. Adelson, E. Bailey, R. R. Bellone, H Blocker, O. Distl, R. C. Edgar, M. Garber, T. Leeb, E. Mauceli, J. N. MacLeod, M. C. T. Penedo, J. M. Raison, T. Sharpe, J. Vogel, L. Andersson, D. F. Antczak, T. Biagi, M. M. Binns, B. P. Chowdhary, S. J. Coleman, G. Della Valle, S. Fryc, G. Guerin, T. Hasegawa, E. W. Hill, J. Jurka, A. Kiialainen, G. Lindgren, J. Liu, E. Magnani, J. R. Mickelson, J. Murray, S. G. Nergadze, R. Onofrio, S. Pedroni, M. F. Piras, T. Raudsepp, M. Rocchi, K. H. Roed, O. A. Ryder, S. Searle, L. Skow, J. E. Swinburne, A. C. Syvanen, T. Tozaki, S. J. Valberg, M. Vaudin, J. R. White, and M. C. Zody. Broad Institute Genome Sequencing, Broad Institute Whole Genome AssemblyLander, E. S., and K. Lindblad-Toh. 2009. Genome sequence, comparative analysis, and population genetics of the domestic horse. Science 326:865-867.

Wessel, D., and U. I. Flügge. 1984. A method for the quantitative recovery of protein in dilute solution in the presence of detergents and lipids. Anal. Biochem. 138:141-143.

Yamaguchi, H., T. Fujimoto, S. Nakamura, K. Ohmura, T. Mimori, F. Matsuda, and S. Nagata. 2010. Aberrant splicing of the milk fat globule-EGF factor 8 (MFG-E8) gene in human systemic lupus erythematosus. Eur. J. Immunol. 40:1778-1785.

Zava, S., C. Barello, A. Pessione, L. Perono Garoffo, P. Fattori, G. Montorfano, A. Conti, C. Giunta, E. Pessione, B. Berra, and M. Giuffrida. 2009. Mare's colostrum globules stimulate fibroblast growth in vitro: A biochemical study. J. Med. Food 12:836-845. 